\title{
Amphetamine Potentiates the Effects of $\beta$-Phenylethylamine through Activation of an Amine-Gated Chloride Channel
}

\author{
Bryan D. Safratowich, ${ }^{1}$ Murad Hossain, ${ }^{1}$ Laura Bianchi, ${ }^{2}$ and Lucia Carvelli ${ }^{1}$ \\ ${ }^{1}$ Department of Pharmacology, Physiology, and Therapeutics, University of North Dakota School of Medicine and Health Sciences, Grand Forks, North \\ Dakota 58202-9037, and 2Department of Physiology and Biophysics, University of Miami, Miller School of Medicine, Miami, Florida 33136
}

\begin{abstract}
$\beta$-Phenylethylamine ( $\beta$ PEA) is a trace amine present in the CNS of all animals tested to date. However, its function is still not fully understood. $\beta$ PEA has been suggested to function as a neurotransmitter and/or to mimic the effect of amphetamine (Amph). In support of the latter is the observation that $\beta$ PEA and Amph produce similar but not identical behaviors. Here, we show that $\beta$ PEA, like Amph, activates the dopamine transporter and the amine-gated chloride channel LGC-55 to generate behaviors in Caenorhabditis elegans. However, although Amph-induced behaviors occurred gradually during 10 min of treatment, $\beta$ PEA induced maximal effects within 1 min. In vitro data demonstrate that $\beta$ PEA activates the LGC-55 more efficiently than Amph $\left(K_{\mathrm{m}}=9\right.$ and $152 \mu \mathrm{M}$, respectively) and generates saturating currents that are 10 times larger than those produced by Amph. These results suggest that activation of LGC-55 mostly accounts for the behavioral effects reached after 1 min of treatment with $\beta$ PEA. Importantly, our in vitro and in vivo data show that Amph increases the effects induced by $\beta$ PEA on the LGC-55, indicating that Amph potentiates the effects generated by the biogenic amine $\beta$ PEA. Together, our data not only identify a new target for $\beta$ PEA, but also offer a novel mechanism of action of Amph. In addition, our results highlight $C$. elegans as a powerful genetic model for studying the effects of biogenic and synthetic amines both at the molecular and behavioral levels.
\end{abstract}

Key words: $\beta$-phenylethylamine; amphetamine; Caenorhabditis elegans; dopamine transporter; ligand-gated ion channels

\section{Introduction}

Phenylethylamines constitute a large class of both biogenic and synthetic compounds. Among the synthetic subgroup, amphetamine (Amph) is well known for its stimulant effects. The biogenic subgroup is comprised of well characterized neurotransmitters such as dopamine (DA), norepinephrine and serotonin, and neurotransmitters broadly named trace amines (TAs), which include $\beta$-phenylethylamine ( $\beta$ PEA). In the mammalian brain, $\beta$ PEA is heterogeneously distributed, with the highest levels found in the nigrostriatal and mesolimbic regions (Paterson et al., 1990). These same areas are vastly innervated by dopaminergic neurons and are sites of action of Amph. $\beta$ PEA is thought to enhance dopaminergic transmission, yet its specific mechanism of action remains uncertain. Changes in $\beta$ PEA metabolism have been found in neurological disorders including schizophrenia and attention deficit hyperactivity disorder (ADHD), suggesting the

\footnotetext{
Received July 19, 2013; revised Feb. 25, 2014; accepted Feb. 26, 2014.

Author contributions: L.C. designed research; B.D.S., M.H., L.B., and L.C. performed research; L.C. analyzed data; L.B. and L.C. wrote the paper.

This work was supported by the National Institutes of Health (Grant R21 DA024797 and NIH-funded COBRE Grant P20 GM103329 to L.C. and Grant R01NS070969 to L.B.) and the American Cancer Society (Grant RGS-09-043-01DDC5 to L.B.). We thank Robert Horvitz, Niel Ringstad, and Mark Alkema for the LGC-55 CDNA; Mark Alkema for the Pglr-1::LGC-55 rescue animals; and Keith Henry for critical reading the manuscript.

The authors declare no competing financial interests.

Correspondence should be addressed to Lucia Carvelli, Department of Pharmacology, Physiology and Therapeutics, University of North Dakota, 504 Hamline St. Grand Forks, ND 58203. E-mail: lucia.carvelli@med.und.edu.

DOI:10.1523/JNEUROSCI.3100-13.2014

Copyright $\odot 2014$ the authors $\quad 0270-6474 / 14 / 344686-06 \$ 15.00 / 0$
}

involvement of this amine in the pathophysiology of monoaminergic systems (Boulton, 1980).

Previous studies showed that $\beta$ PEA inhibits the uptake and promotes the release of the monoamines DA, norepinephrine, and, to a lesser extent, serotonin. The potency of $\beta$ PEA in increasing the concentration of these neurotransmitters is comparable to that of Amph (Nakamura et al., 1998). When applied exogenously, $\beta$ PEA elicits Amph-like psychostimulant responses (Bergman et al., 2001). Interestingly, the stimulant effects generated by $\beta$ PEA are transient compared with those generated by Amph and, like Amph, $\beta$ PEA releases DA in a manner dependent on the presence of an intact DA transporter (DAT; Sotnikova et al., 2004; Hossain et al., 2013). Subsequent experiments demonstrated that a subset of behavioral responses to $\beta$ PEA were independent from DAT, suggesting that $\beta$ PEA acted on other unidentified targets (Sotnikova et al., 2005). In this study, we used the model organism Caenorhabditis elegans to investigate the effects of $\beta$ PEA and Amph in both in vivo and in vitro settings. We show that $\beta$ PEA requires the amine-gated chloride channel LGC-55 to generate behaviors distinct from those induced by Amph. In fact, $\beta$ PEA induced maximal behavioral effects within $1 \mathrm{~min}$ of treatment, whereas Amph required at least $10 \mathrm{~min}$ to generate the same effects. Our in vitro data show that $\beta$ PEA actives the LGC-55 channels more efficiently than Amph $\left(K_{\mathrm{m}}=9\right.$ and $152 \mu \mathrm{M}$, respectively; Safratowich et al., 2013) and generates larger currents than Amph (3.7 and $0.4 \mu \mathrm{A}$, respectively; Safratowich et al., 2013). We suggest that these differences explain the diverse effects observed in vivo; that is, the faster onset of $\beta$ PEA- 

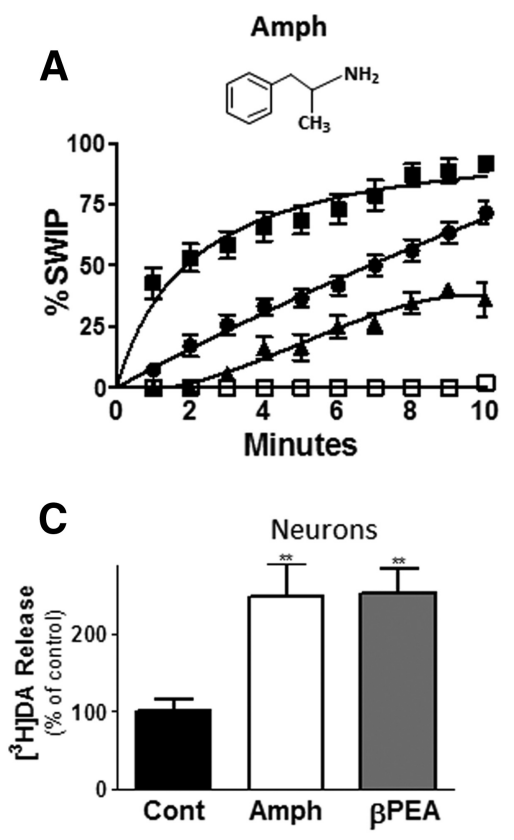
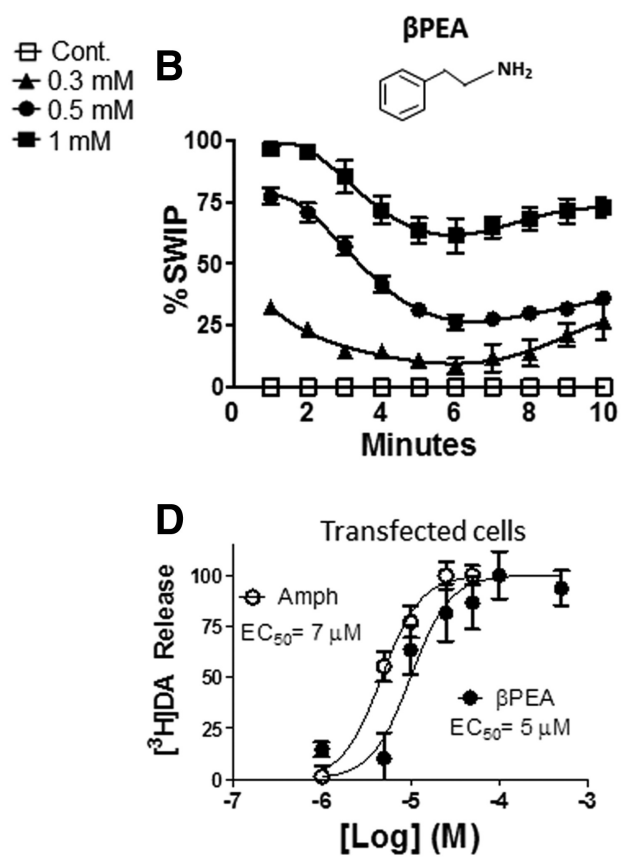

Figure 1. In vivo and in vitro effects of $\beta$ PEA and amphetamine treatments in C. elegans. $\boldsymbol{A}$, In WT animals $0,0.3,0.5$, and $1 \mathrm{~mm}$ Amph caused $0 \%, 36 \%, 65 \%$, and $92 \%$ SWIP, respectively, after 10 min of treatment. These results are reproduced with permission from Safratowich et al. (2013). $\boldsymbol{B}$, Concentrations of 0, 0.3, 0.5, and $1 \mathrm{~mm} \beta$ PPEA induced 0\%, 32\%, 77\%, and 96\% SWIP after 1 min; $0 \%, 14 \%, 41 \%$, and $72 \%$ SWIP after 4 min; and $0 \%, 26 \%, 36 \%$, and $73 \%$ after 10 min, respectively. All $\beta$ PEA concentrations tested after 1 min induced SWIP levels that were statistically different with respect to SWIP in control-treated animals $(p=0.001$, two-way ANOVA with Bonferroni's posttest). The number of animals ( $n$ ) tested in the control ( $0 \mathrm{~mm} \beta P E A), 0.3,0.5$, and $1 \mathrm{~mm} \beta P E A$ groups were 179, 66, 285 and 92, respectively. C, $\beta$ PEA and Amph caused similar [ ${ }^{3} \mathrm{H}$ ]DA release in C. elegans cultured neurons. Data are the average of three independent experiments. $D$, The $\mathrm{EC}_{50}$ for $\left[{ }^{3} \mathrm{H}\right] \mathrm{DA}$ release measured in DAT-1-transfected LLC-pk1 cells did not show statistical differences between $\beta$ PEA and Amph treatments (Student's $t$ test). The experiment was repeated three times and, during each experiment, concentrations were replicated in three wells.

induced behavioral effects with respect to Amph. Importantly, both our in vitro and in vivo results demonstrate that Amph potentiates the activation of the LGC-55 channels by $\beta$ PEA. Therefore, our data identify a new target for $\beta$ PEA and support a novel mechanism of action of Amph.

\section{Materials and Methods}

C. elegans strains and behavioral assays. Nematode husbandry and swimming-induced paralysis (SWIP) assays were performed as described in Safratowich et al. (2013). Wild-type (WT; Bristol N2) and knock-out (KO) strains dat-1 (ok157)III, cat-2(e1112)II, dop-1(vs100)X, dop-2(vs105)V, dop3(ok295)X, dop-4(tm1392)X, ser-2(pk1357)X, ser-3(ok1995)I, ser-4(ok512)III, tyra-3(ok325)X, lgc-53(n4330)X, and lgc-55(n4311)V were obtained from the C. elegans Genetics Center at the University of Minnesota (Minneapolis). Rescue animals lgc-55(tm2913); lin-15(n765ts; zfEx42 [pglr-1::LGC-55] were kindly donated by Dr. Mark Alkema (University of MassachusettsWorcester). At least 60 animals were tested in each group in at least five independent trials. The exact number of animals used per group is shown in the figure legends. Behavioral data were analyzed statistically using one-way ANOVA with Bonferroni's multiple-comparison test unless otherwise indicated.

Oocyte expression and electrophysiology. Complementary RNAs (cRNA) synthesis, oocyte injection, and TEVC experiments were performed as described in Safratowich et al. (2013). Figure $1 A$ is used with permission from Safratowich et al. (2013) and is provided here as visual for a direct comparison with $\beta$ PEA data.

$\left[{ }^{3} H\right] D A$ release assays in $\mathrm{C}$. elegans primary cultures and transfected cells. We prepared C. elegans primary cultures as described in Carvelli et al. (2004). Two-day-old embryonic cells $\left(10^{6}\right.$ cells/well $)$ were preloaded with $5 \mathrm{~nm}\left[{ }^{3} \mathrm{H}\right] \mathrm{DA}$ for $30 \mathrm{~min}$ at room temperature. Cells were washed five times and then $100 \mu \mathrm{M} \beta$ PEA or Amph was applied for $1 \mathrm{~min}$.
Samples were collected and counted for radioactivity. $\mathrm{EC}_{50}$ values were calculated in LLCpk1 cells transfected with $0.5 \mu \mathrm{g}$ of C. elegans DAT (DAT-1) cDNA and maintained in EMEM with $5 \%$ FBS, $100 \mathrm{U} / \mathrm{ml}$ penicillin, and 100 $\mathrm{mg} / \mathrm{ml}$ streptomycin. Cells were preincubated with $20 \mathrm{~nm}\left[{ }^{3} \mathrm{H}\right] \mathrm{DA}$ and treated with $0.001-0.5$ mM $\beta$ PEA or Amph. Nisoxetine $(100 \mu \mathrm{M})$ was used to calculate specific release because it was shown previously to inhibit $\left[{ }^{3} \mathrm{H}\right] \mathrm{DA}$ uptake $\left(K_{\mathrm{i}}=3 \mathrm{nM}\right)$ in DAT-1-transfected cells (Jayanthi et al., 1998).

\section{Results}

$\beta$ PEA- and amphetamine-induced behaviors in C. elegans

We showed previously that increased extracellular DA levels generated a potent inhibitory effect on the ability of $C$. elegans to swim. We named this behavior SWIP. Genetic ablation (McDonald et al., 2007) or pharmacological blockage of DAT-1 (Carvelli et al., 2008) was sufficient to cause SWIP. Not surprisingly Amph, which is a DAT substrate and a DA releaser, also induced SWIP (Carvelli et al., 2010; Safratowich et al., 2013). In fact, animals treated with 0.3-1 mM Amph exhibited SWIP within $10 \mathrm{~min}$ (Fig. 1A, used with permission from Safratowich et al., 2013). Here, we found that animals challenged with $0.3-1 \mathrm{mM} \beta$ PEA exhibited SWIP in a dose-dependent manner (Fig. 1B). However, whereas Amph maximal effect occurred after $10 \mathrm{~min}, \beta$ PEA caused maximal SWIP within a few seconds. Moreover, the maximal SWIP levels reached with Amph lasted until Amph was washed out, whereas the maximal SWIP levels generated by $\beta$ PEA decreased over time despite the sustained presence of the drug. This time-dependent decrease of $\beta$ PEAinduced SWIP was inversely proportional to the concentration of $\beta$ PEA used. For example, when treated with $0.5 \mathrm{~mm} \beta \mathrm{PEA}, 71 \pm$ $2 \%$ of animals recovered from SWIP after 6 min (Fig. $1 B, 0$ ), whereas with $1 \mathrm{mM} \beta \mathrm{PEA}$, only $36 \pm 4 \%$ animals recovered from SWIP (Fig. $1 B, \boldsymbol{\square}$ ), suggesting that the decrease of SWIP is specifically linked to $\beta$ PEA treatment. Together, these results demonstrate that the kinetics for $\beta$ PEA-induced SWIP are distinct from those of Amph.

We have also shown previously that Amph-induced SWIP is caused in part by an increase of extracellular DA released through DAT-1 (Carvelli et al., 2010). To determine whether the difference in the extent of SWIP between $\beta$ PEA and Amph at 1 min was caused by elevated DA release, we compared the ability of $\beta$ PEA and Amph to increase the extracellular levels of DA. Cultured $C$. elegans DA neurons were preloaded with $\left[{ }^{3} \mathrm{H}\right] \mathrm{DA}$ and then treated with $\beta$ PEA or Amph for $1 \mathrm{~min}$. Both drugs induced significant increases of extracellular $\left[{ }^{3} \mathrm{H}\right] \mathrm{DA}$ with respect to controls $\left(253 \pm 31 \%\right.$ and $248 \pm 41 \%$, respectively; ${ }^{* *} p=0.003$, one-way ANOVA with Bonferroni's posttest), but no difference was observed between $\beta$ PEA and Amph treatments (Fig. 1C). Moreover, the $\mathrm{EC}_{50}$ calculated for DA release induced by $\beta \mathrm{PEA}$ $(5 \pm 0.05 \mu \mathrm{M})$ and Amph $(7 \pm 0.08 \mu \mathrm{M})$ in DAT-1-transfected cells revealed no significant difference (Student's $t$ test; Fig. 1D). These results suggested that the higher SWIP rates measured with 

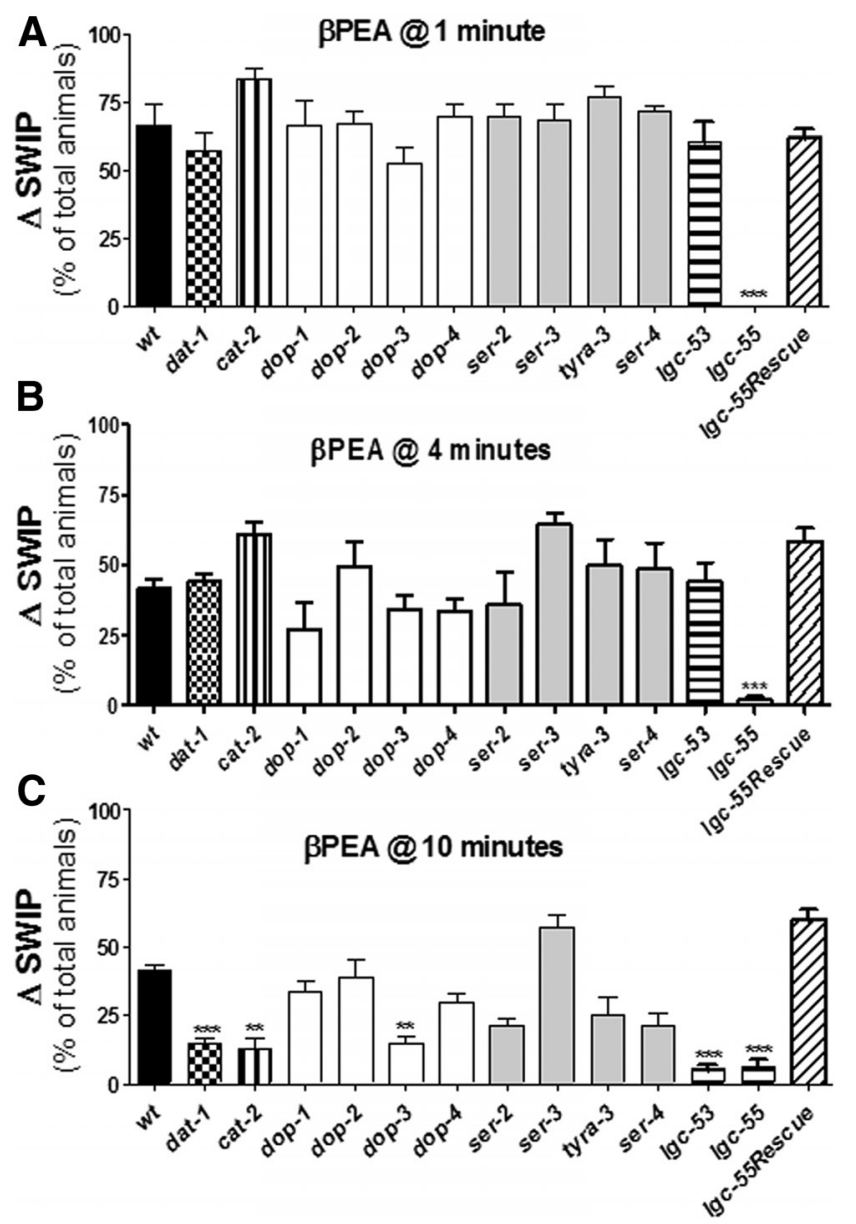

Figure 2. Proteins required for $\beta$ PEA-induced SWIP at different time points. DAT-1 (dat-1), DA (cat-2), DA receptors (dop-1, dop-2, dop-3, dop-4), trace amine receptors (ser-2, ser-3, tyra-3, ser-4), and the amine-gated channel lgc-53 KOs did not exhibit statistically differences in SWIP with respect to WT after $1(\boldsymbol{A})$ and $4(\boldsymbol{B})$ minutes of $0.5 \mathrm{~mm} \beta$ PEEA treatment (one-way ANOVA with Bonferroni's posttest). The LGC-55 KO (Igc-55) showed $100 \%$ and $95 \%$ reduction in SWIP after $1(\boldsymbol{A})$ and $4 \mathrm{~min}(\boldsymbol{B})$ of treatment, respectively. $\boldsymbol{C}$, After $10 \mathrm{~min}$, dat-1, cat-2, dop-3, $\operatorname{lgc}-53$, and $\operatorname{lgc}-55 \mathrm{KO}$ s exhibited significant reductions in SWIP with respect to WT animals $\left({ }^{* * *} p=0.0001 ;{ }^{* *} p=0.001\right.$, one-way ANOVA with Bonferroni's posttest). Igc-55 expression driven by the $g / r-1$ promoter in $1 g c-55 \mathrm{KO}$ animals rescued the $\beta$ PEA-induced SWIP phenotype after 1, 4, and $10 \mathrm{~min}$. As the dat-1 K0s showed basal SWIP, we reported the $\Delta$ SWIP as the number of paralyzed animals upon $\beta$ PEA treatment minus the number of paralyzed animals upon vehicle treatment. In $\boldsymbol{A}-\boldsymbol{C}$, mutants were compared with WT animals using one-way ANOVA with Bonferroni's posttest. The numbers of animals per each group were as follows: $\mathrm{WT}=98$, dat $-1=67$, cat $-2=69$, dop $-1=66$, dop $-2=60$, dop $-3=69$, dop $4=60$, ser $-2=69$, ser- $3=63$, tyra $-3=65$, ser $-4=62, \operatorname{lgc}-53=68, \operatorname{lgc}-55=67$, and $\operatorname{lgc}-55$ Rescue $=127$.

$\beta$ PEA are not caused by the ability of $\beta$ PEA to release larger amounts of DA with respect to Amph.

\section{$\beta$ PEA induces behaviors independently from DAT, DA, and} TA receptors

We showed previously that Amph-induced SWIP requires a functional DAT-1 (Carvelli et al., 2010; Safratowich et al., 2013). To investigate whether $\beta$ PEA-induced SWIP was dependent on DAT-1, we measured $\beta$ PEA-induced SWIP in DAT-1 KO animals (dat-1) after 1 min of treatment. We found that $\beta$ PEA caused similar levels of SWIP in dat-1 compared with WT animals (Fig. 2A). Next, we tested whether DA itself was involved in generating the high SWIP levels induced by $\beta$ PEA after $1 \mathrm{~min}$. We measured $\beta$ PEA-induced SWIP in cat-2 KO animals that lack tyrosine hydroxylase, a key enzyme for DA synthesis (Sanyal et al., 2004) and no difference was found with respect to WT (Fig. $2 A$ ). We then investigated the possibility that $\beta$ PEA itself binds directly to DA receptors and induces fast SWIP. However, in animals with the D1-like (dop-1, dop-4) or D2-like (dop-2, dop-3) DA receptors knocked out (Suo et al., 2002; Chase and Koelle, 2007; Sugiura et al., 2005), we found no difference in $\beta$ PEA-induced SWIP with respect to WT animals (Fig. 2A). Together, these data demonstrate that the DAT-1, DA, and DA receptors are not required to generate $\beta$ PEA-induced SWIP after 1 min of treatment.

Next, we investigated whether $\beta$ PEA activated the TA receptors to generate high SWIP rates. We measured $\beta$ PEA-induced SWIP in animals lacking the tyramine SER-2 (Rex and Komuniecki, 2002), the octopamine SER-3 (Suo et al., 2006), the tyramine/octopamine TYRA-3 (Wragg et al., 2007), and the serotonin receptor SER-4 (Hamdan et al., 1999) and the knock-out of these TA receptors did not affect $\beta$ PEA-induced SWIP after 1 min of treatment (Fig. 2A). To conclude, these data demonstrate that the high SWIP levels measured after 1 min of $\beta$ PEA treatment do not require DA or DAT-1, suggesting that $\beta$ PEA itself may be a neurotransmitter acting on targets other than DA and TA receptors.

$\beta$ PEA-induced behaviors require LGC-55 channels

Two amine-gated chloride channels, LGC-53 and LGC-55, have been identified in C. elegans by Ringstad et al. (2009) and Pirri et al. (2009). Both groups showed strong expression of LGC-55 in several head neurons and in neck muscle cells. We demonstrated recently that Amph-induced SWIP depends on both DAT-1 and the LGC-55 (Safratowich et al., 2013). Given the chemical structure similarities between Amph and $\beta$ PEA (Fig. $1 A, B$ ), we reasoned that the LGC-55 and/or LGC-53 receptors might be activated by $\beta$ PEA to generate high rates of SWIP. In the LGC-53 $\mathrm{KO}$ animals (lgc-53), $\beta$ PEA-induced SWIP levels were equivalent to those observed in WT (Fig. 2A), suggesting that these channels are not required to generate SWIP after 1 min of $\beta$ PEA treatment. In contrast, when LGC-55 KO animals (lgc-55) were challenged with $\beta$ PEA, we did not observe SWIP after 1 min of treatment ${ }^{* * *} p=0.0001$, one-way ANOVA with Bonferroni's posttest; Fig. $2 A$ ). These results support that LGC-55 channels are required to generate $\beta$ PEA-induced SWIP. We also investigated the effect of $\beta$ PEA at later time points in WT, $\operatorname{lgc}-53$, and $\operatorname{lgc}-55$ (Fig. $2 B$ ) and found that, after $4 \mathrm{~min}$, only the lgc-55 animals showed significantly reduced SWIP with respect to WT $\left({ }^{* *} p=0.0001\right.$, oneway ANOVA with Bonferroni's posttest). However, after $10 \mathrm{~min}$ of treatment (Fig. 2C), a strong reduction in SWIP was measured in both $l g c-55$ and $l g c-53$ ( $88 \pm 2 \%$ and $85 \pm 3 \%$, respectively; ${ }^{* * *} p=0.0001$, one-way ANOVA with Bonferroni's posttest). Interestingly, SWIP could be fully rescued when lgc-55 cDNA fused to $g l r-1$ promoter was introduced into the $\operatorname{lgc}-55 \mathrm{KO}$ animals (Pirri et al., 2009; Fig. 2A-C). This demonstrates that the expression of LGC-55 and its functional complementation in neurons, but not in muscle cells, is required to generate SWIP. In fact, the $g l r-1$ promoter, which encodes an AMPA-like ionotropic glutamate receptor, drives $\lg c-55$ expression only in 17 C. elegans neurons, including motoneurons (Hart et al., 1995; Maricq et al., 1995). The lgc-55-rescued animals, like WT animals (Fig. $1 A, B$ ), did not show SWIP when tested in control solution. In fact, after 1,4 , and $10 \mathrm{~min}$ of exposure to control solution, only $0 \%, 0 \%$, and $1.6 \pm 1 \%$ animals exhibited SWIP, respectively. Together, these data demonstrate that neuronally expressed LGC- 55 receptors are needed to generate $\beta$ PEA-induced SWIP, whereas the LGC-53 receptors are recruited only at later time points. 
A

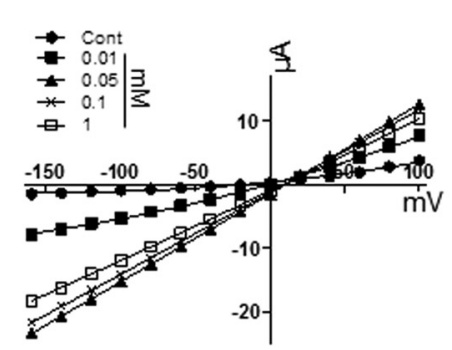

B

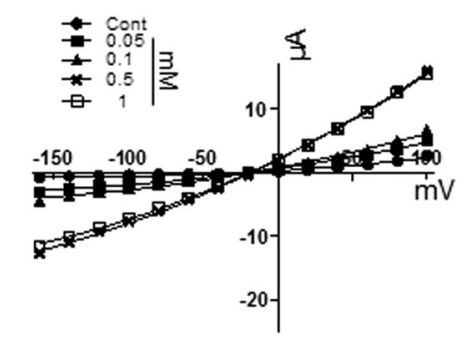

C

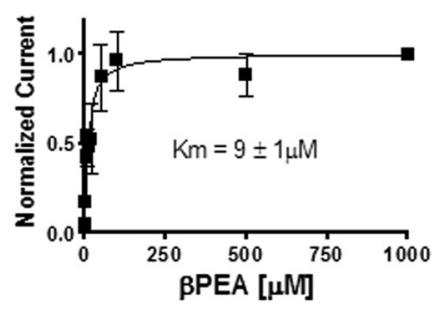

Figure 3. $\beta P E A$ activates the LGC-55 channels more efficiently than Amph. $\boldsymbol{A}, \boldsymbol{B}$, Representative current-voltage relationships generated in lgc-55-injected 0ocytes perfused with $\beta P E A$ ( $n=12$ ) or Amph $(n=16)$, respectively. C, Dose-response curve of $\beta$ PEA-induced currents generated when the oocyte membrane potential was held at $-60 \mathrm{mV}(n=12)$. Currents were normalized to the maximal current value and fitted to a Michaelis-Menten equation.

\section{After prolonged treatments, $\beta$ PEA-induced SWIP involves proteins other than LGC-55}

Our results (Fig. $1 B$ ) indicate that $0.3-1 \mathrm{mM} \beta$ PEA induces high levels of SWIP within the first minute of treatment, with reduction of SWIP after 3-6 min, followed by a slight increase of SWIP at minutes $8-10$. To investigate the basis for these kinetics, we performed SWIP assays after 4 and $10 \mathrm{~min}$ in mutant animals. We found that, after $4 \mathrm{~min}$ (Fig. $2 B$ ), the DA and TA receptor CAT-2 and DAT-1 KOs exhibited no significant differences in SWIP with respect to WT animals (one-way ANOVA with Bonferroni's posttest). Interestingly, though, after $10 \mathrm{~min}$ (Fig. 2C), only animals lacking the DAT-1, DA (cat-2) and the DA receptor DOP-3 exhibited significant SWIP reduction with respect to WT (66 \pm $2 \%, 68 \pm 2 \%$, and $66 \pm 3 \%$, respectively; ${ }^{* *} p=0.001$ and ${ }^{* * *} p=$ 0.0001 , one-way ANOVA with Bonferroni's posttest). These results demonstrate that, after $10 \mathrm{~min}, \beta$ PEA likely recruits the same key players as Amph to induce SWIP (Carvelli et al., 2010; Safratowich et al., 2013).

Collectively, the experiments shown in Figure 2 demonstrate that only the LGC-55 receptors, which are expressed in GLR-1expressing neurons, are required to generate $\beta$ PEA-induced SWIP within $1 \mathrm{~min}$.

\section{$\beta$ PEA activates the LGC-55 channels directly}

Our data demonstrate that LGC- 55 is needed by $\beta$ PEA to generate SWIP within a few minutes of treatment (Fig. $2 A, B$ ). Therefore, we investigated whether $\beta$ PEA, like Amph (Safratowich et al., 2013), activates the LGC-55 directly. We performed two electrode voltage-clamp experiments in Xenopus oocytes injected with lgc-55 cRNA and found that increasing $\beta$ PEA concentrations evoked currents in a dose-response manner (Fig. 3A). Interestingly, 0.01-1 mM $\beta$ PEA generated larger currents than equivalent concentrations of Amph (cf. Fig. $3 A, B$ ). Indeed, the $K_{\mathrm{m}}$ calculated for $\beta$ PEA-induced currents (Fig. $3 C$ ) was 17 times lower than the $K_{\mathrm{m}}$ previously calculated for Amph-induced currents (152 $\pm 29 \mu \mathrm{M}$; Safratowich et al., 2013). Moreover, a saturating concentration of $\beta$ PEA gave a current $(3.7 \pm 0.6 \mu \mathrm{A})$ larger than that seen previously with a saturating concentration of Amph (0.4 $\pm 0.09 \mu \mathrm{A}$; Safratowich et al., 2013). Therefore, the comparison between $\beta$ PEA and Amph efficacy reveals that $\beta$ PEA is more potent at LGC- 55 because it activates the receptor at lower concentrations and produces larger currents than Amph.

\section{Amph potentiates the effects of $\beta$ PEA on the LGC-55 channels}

Given the different efficiencies of Amph and $\beta$ PEA to activate LGC-55, we investigated whether Amph interfered with $\beta$ PEA in
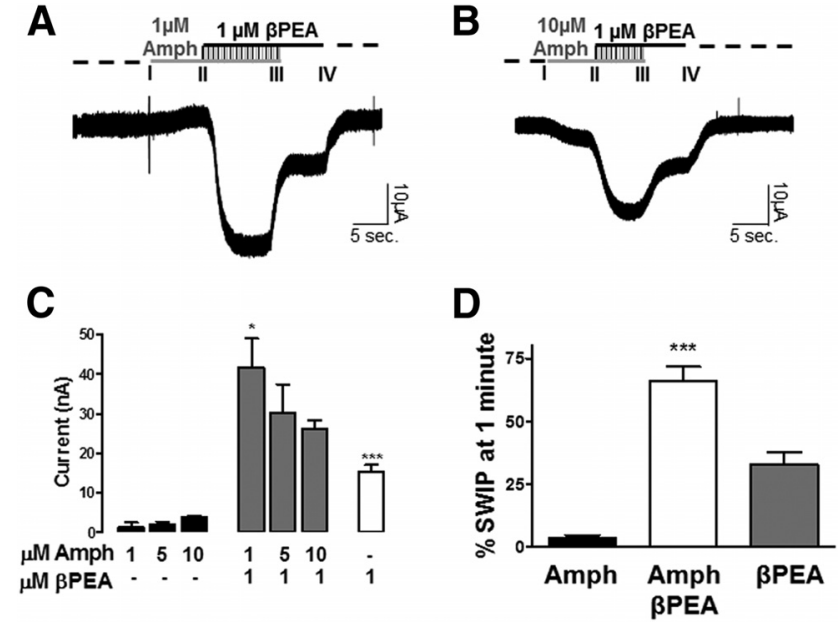

Figure 4. Amph potentiates the LGC-55 activation by $\beta$ PEA. Representative recordings of 10 LGC-55-expressing oocytes perfused with $1 \mu \mathrm{M}(\boldsymbol{A})$ or $10 \mu \mathrm{M}(\boldsymbol{B})$ Amph alone (I-II). Subsequently, $1 \mu \mathrm{m} \beta$ PEEA was added together with 1 or $10 \mu \mathrm{m}$ Amph (II-III). Amph was removed and $\beta$ PEA was perfused alone (III-IV). $\boldsymbol{C}$, Average of currents as measured in $\boldsymbol{A}$ and $\boldsymbol{B}$. Currents measured during Amph/ $\beta$ PEA coperfusion were statistically higher than those obtained with $\beta$ PEA alone ( ${ }^{* * *} p \leq 0.0001$, one-way ANOVA with Bonferroni's posttest). Coperfusion of $1 \mu \mathrm{m}$ Amph generated a higher potentiation of $\beta$ PEA-induced currents with respect to $10 \mu \mathrm{m}$ Amph $\left({ }^{*} p=0.03\right.$, one-way ANOVA with Bonferroni's posttest). D, After $1 \mathrm{~min}$, animals cotreated with $500 \mu \mathrm{m}$ Amph and $300 \mu \mathrm{m} \beta$ PEA $(n=92)$ exhibited higher SWIP with respect to animals treated with Amph alone $(n=65)$ or $\beta$ PEA alone $(n=61)\left({ }^{* * *} p=0.0001\right.$, one-way ANOVA with Bonferroni's posttest).

activating the LGC-55. We perfused Amph alone (Fig. $4 A, B$, I-II) and together with $\beta$ PEA (Fig. $4 A, B$, II-III) onto oocytes expressing LGC-55. Amph perfusion was discontinued to measure $\beta$ PEA-induced currents (Fig. $4 A, B$, III-IV). Interestingly, we found that $\beta$ PEA-induced currents were potentiated in presence of Amph. Indeed, $1 \mu \mathrm{M} \beta$ PEA generated currents of $15 \pm 2 \mu \mathrm{A}$, whereas 1, 5, and $10 \mu \mathrm{M}$ Amph generated currents of 1.3, 2, and 4 $\mu \mathrm{A}$, respectively (Fig. $4 C$ ). However, when $1 \mu \mathrm{M} \beta$ PEA was perfused together with 1,5 , or $10 \mu \mathrm{M} A \mathrm{mph}$, we measured currents of 42,30 , and $26 \mu \mathrm{A}$, respectively (Fig. $4 C$ ). Interestingly, the potentiation effect of $1 \mu \mathrm{M}$ Amph was significantly higher than that measured with $10 \mu \mathrm{M}$ Amph $\left({ }^{*} p=0.01\right.$, one-way ANOVA with Bonferroni's posttest). Finally, we investigated whether Amph could modulate the in vivo activity of the LGC-55 during $\beta$ PEA stimulation. We cotreated animals with Amph/ $\beta \mathrm{PEA}$ and found that, after $1 \mathrm{~min}$, they exhibited $66 \pm 5 \%$ SWIP, whereas when applied separately, the two drugs generated $3 \pm 2 \%$ and $32 \pm 5 \%$ SWIP, respectively (Fig. $4 D$ ). These results demonstrate that Amph potentiates $\beta$ PEA-induced effects in vivo. In fact, Amph/ $\beta$ PEA- 
induced SWIP was approximately twice as high as the values we expected if the effects of the two drugs were purely additive.

To conclude, these data demonstrate that both in vitro and in vivo Amph potentiates the effects induced by $\beta$ PEA. Specifically, $1 \mu \mathrm{M} \mathrm{Amph} / \beta$ PEA generated currents that were 30 or 3 times larger than those generated by $1 \mu \mathrm{M}$ Amph or $\beta$ PEA alone, respectively (Fig. $4 C$ ). Similarly, Amph/ $\beta$ PEA cotreatment generated SWIP values that were 20 or 2 times higher than those generated by each individual drug, respectively (Fig. $4 D$ ).

\section{Discussion}

In vitro and in vivo studies have suggested that $\beta$ PEA is an endogenous psychostimulant that shares similar mechanisms of action with Amph (Gilbert and Cooper, 1983; Janssen et al., 1999). Like Amph, $\beta$ PEA induces DA efflux through DAT, but generates only transient Amph-like behaviors. One explanation that has been brought forward for this difference is that $\beta \mathrm{PEA}$ is degraded more readily than Amph by the monoamine oxidase type B (MAO-B; Bergman et al., 2001). Interestingly, in DAT KO mice, which are hyperactive (Giros et al., 1996), $\beta$ PEA and Amph still increased extracellular DA and produced certain stereotypes, indicating that targets other than DAT and DA are responsible for some of the behaviors generated by phenylethylaminic compounds (Carboni et al., 2001; Sotnikova et al., 2004; Sotnikova et al., 2005; Safratowich et al., 2013). Here, we have investigated the effects of $\beta$ PEA and Amph both at the molecular and behavioral levels and found similarities and differences, as well as functional interactions in the mechanism of action of these two compounds.

Our previous data showed that in C. elegans Amph requires both key components of the dopaminergic system (DA, DAT-1, receptors) and the LGC-55 channels to generate gradual paralysis within 10 min (Carvelli et al., 2010; Safratowich et al., 2013). The present study demonstrates that $\beta$ PEA acts on the same targets to affect behaviors in C. elegans. However, these studies uncovered distinct kinetics differences in the action of the two compounds. $\beta$ PEA recruited LGC- 55 within a few seconds of its application to generate maximal SWIP. The involvement of DAT-1, DA, and DOP-3 in $\beta$ PEA-induced SWIP was only observed after prolonged treatments, which coincides with the temporal action of Amph (Carvelli et al., 2010). It is unlikely that these timedependent outcomes are due to permeability differences between the two compounds, because Amph and $\beta$ PEA have comparable lipophilic values ( $\log \mathrm{P}=1.8$ and 1.4, respectively). Interestingly, our in vitro data demonstrate that $\beta$ PEA activated the LGC-55 more efficiently and generated larger currents than Amph (Fig. 3 ), suggesting that the larger currents generated by $\beta$ PEA underlie the robust behaviors generated by this compound. Together, our data support the hypothesis that $\beta$ PEA acts via two different mechanisms: (1) the robust activation of the LGC-55 channels (Fig. 3), which generates high SWIP levels within a few seconds (Fig. 1B), followed by (2) DA efflux through DAT-1 (Fig. 1C,D), which activates the DOP-3 receptors to generate SWIP (Fig. 2C). These conclusions are also supported by the observation that lgc-55 KOs did not exhibit SWIP, whereas cell-specific rescue experiments showed that reexpression of lgc-55 cDNA in 17 classes of neurons fully restored SWIP in the lgc-55 KO animals (Fig. 2). These results provide direct in vivo evidence that $\beta$ PEAactivated LGC-55 receptors mediate neuronal function in C. elegans. Finally, we exclude the possibility that the higher SWIP levels measured with $\beta$ PEA after 1 min are caused by high levels of extracellular DA, because $\beta$ PEA and Amph induced similar levels of DA release in neuronal culture (Fig. 1C).
Similarly to mammalian systems, our data show that behaviors induced by $\beta$ PEA in $C$. elegans had a short-lasting effect compared with Amph (Fig. 1A,B). The mechanism underlying these results remains unclear, although faster degradation of $\beta$ PEA could be possible because MAO homologs have been identified in C. elegans (Weyler, 1992). However, we speculate that SWIP recovery cannot be explained by faster $\beta$ PEA degradation as animals are continually immersed in a solution containing $\beta$ PEA (Fig. 1B).

The LGC-55 channels are members of the cys-loop ligandgated ion channel (LGIC) receptors superfamily (Pirri et al., 2009; Ringstad et al., 2009), which includes the well studied mammalian nicotinic acetylcholine, $5 \mathrm{HT}_{3}$, glycine, and GABA (type A and C) receptors (Sine and Engel, 2006). Previous data have shown that the activation of the LGIC is not simply a direct consequence of substrate binding, but rather is a multistep process in which binding of the ligand induces conformation changes into the so-called "flip state" from which the channel shifts into its open configuration (Farrant and Kaila, 2007; Lape et al., 2008). Full and partial agonists enable receptors to transition from the inactivated to the activated state with different efficiencies, with full agonists exhibiting a more efficient transition into the flip state. Our data show that $\beta$ PEA activates the LGC-55 channels more efficiently than Amph and generates larger currents than those generated by Amph (Fig. 3), suggesting that $\beta P E A$ and Amph act as full and partial agonists for LGC-55, respectively. This phenomenon, which was reported for $\mathrm{GABA}_{\mathrm{A}}$ and glycine receptors, can be potentiated by neurosteroids, benzodiazepines, anesthetics, and ethanol (Mihic et al., 1997). Similarly, our data suggest that Amph amplifies the transient behavioral effects induced by $\beta$ PEA by potentiating the activity of the LGC-55 (Fig. 4). Considering that low Amph concentrations are used to treat ADHD, our observation that $1 \mu \mathrm{M}$ Amph potentiates the effect of $\beta$ PEA on LGC- 55 channels might have important physiologic implications if LGC-55 homologs are present in humans. The existence of amine-gated channels in mammals has long been suggested (Yang and Hatton, 1994). More recently, Hatton and Yang (2001) demonstrated that, in the brain, histamine generates fast IPSPs through the activation of as-yetunidentified chloride channels. In fact, these receptors are distinct from the well known ionotropic GABA and glycine receptors because they are insensitive to bicuculline or strychnine. Interestingly, we have screened the human protein database and found four orphan proteins sharing $30-45 \%$ identity with LGC-55 at the amino acid level, providing evidence that LGC-55 homologs might indeed exist in humans.

\section{References}

Bergman J, Yasar S, Winger G (2001) Psychomotor stimulant effects of b-phenylethylamine in monkeys treated with MAO-B inhibitors. Psychopharmacology (Berl) 159:21-30. CrossRef

Boulton AA (1980) Trace amines and mental disorders. Can J Neurol Sci 7:261-263. Medline

Carboni E, Spielewoy C, Vacca C, Nosten-Bertrand M, Giros B, Di Chiara G (2001) Cocaine and amphetamine increase extracellular dopamine in the nucleus accumbens of mice lacking the dopamine transporter gene. J Neurosci RC141: 1-4Medline

Carvelli L, McDonald PW, Blakely RD, Defelice LJ (2004) Dopamine transporters depolarize neurons by a channel mechanism. Proc Natl Acad Sci U S A 101:16046-16051. CrossRef Medline

Carvelli L, Blakely RD, DeFelice LJ (2008) Dopamine transporter/syntaxin $1 \mathrm{~A}$ interactions regulate transporter channel activity and dopaminergic synaptic transmission. Proc Natl Acad Sci US A 105:14192-14197. CrossRef Medline

Carvelli L, Matthies DS, Galli A (2010) Molecular mechanisms of amphet- 
amine actions in Caenorhabditis elegans. Mol Pharmacol 78:151-156. CrossRef Medline

Chase D, Koelle M (2007) Biogenic amine neurotransmitters in C. elegans. WormBook 1-15. Medline

Farrant M, Kaila K (2007) The cellular, molecular and ionic basis of GABA(A) receptor signalling. Prog Brain Res 160:59-87. CrossRef Medline

Gilbert D, Cooper SJ (1983) beta-Phenylethylamine-, d-amphetamine- and l-amphetamine-induced place preference conditioning in rats. Eur J Pharmacol 95:311-314. CrossRef Medline

Giros B, Jaber M, Jones SR, Wightman RM, Caron MG (1996) Hyperlocomotion and indifference to cocaine and amphetamine in mice lacking the dopamine transporter. Nature 379:606-612. CrossRef Medline

Hamdan FF, Ungrin MD, Abramovitz M, Ribeiro P (1999) Characterization of a novel serotonin receptor from Caenorhabditis elegans: cloning and expression of two splice variants. J Neurochem 72:1372-1383. CrossRef Medline

Hart AC, Sims S, Kaplan JM (1995) Synaptic code for sensory modalities revealed by C. elegans GLR-1 glutamate receptor. Nature 378:82-85. CrossRef Medline

Hatton GI, Yang QZ (2001) Ionotropic histamine receptors and H2 modulate supraoptic oxytocin neuronal excitability and dye coupling. J Neurosci 21:2974-2982. Medline

Hossain M, Wickramasekara RN, Carvelli L (2013) $\beta$-phenylethylamine requires the dopamine transporter to increase extracellular dopamine in Caenorhabditis elegans dopaminergic neurons. Neurochem Int, in press. CrossRef Medline

Janssen PA, Leysen JE, Megens AA, Awouters FH (1999) Does phenylethylamine act as endogenous amphetamine in some patients? Int J Neuropsychopharmacol 2:229-240. CrossRef Medline

Jayanthi LD, Apparsundaram S, Malone MD, Ward E, Miller DM, Eppler M, Blakely RD (1998) The Caenorhabditis elegans gene T23G5.5 encodes an antidepressant- and cocaine-sensitive dopamine transporter. Mol Pharmacol 54:601-609. Medline

Lape R, Colquhoun D, Sivilotti LG (2008) On the nature of partial agonism in the nicotinic receptor superfamily. Nature 454:722-727. CrossRef Medline

Maricq AV, Peckol E, Driscoll M, Bargmann CI (1995) Mechanonosensory signaling in C. elegans mediated by the GLR-1 glutamate receptor. Nature 378:78-81. CrossRef Medline

McDonald PW, Hardie SL, Jessen TN, Carvelli L, Matthies DS, Blakely RD (2007) Vigorous motor actvitiy in Caenorhabditis elegans requires efficient clearance of dopamine mediated by synaptic localization of the dopamine transporter DAT-1. J Neurosci 27:14216-14227. CrossRef Medline

Mihic SJ, Ye Q, Wick MJ, Koltchine VV, Krasowski MD, Finn SE, Mascia MP, Valenzuela CF, Hanson KK, Greenblatt EP, Harris RA, Harrison NL (1997) Sites of alcohol and volatile anaesthetic action on GABAA and glycine receptors. Nature 389:385-389. CrossRef Medline

Nakamura M, Ishii A, Nakahara D (1998) Characterization of betaphenylethylamine-induced monoamine release in rat nucleus accumbens: a microdialysis study. Eur J Pharmacol 349:163-169. CrossRef Medline
Paterson IA, Juorio AV, Boulton AA (1990) 2-Phenylethylamine: a modulator of catecholamine transmission in the mammalian central nervous system? J Neurochem 55:1827-1837. CrossRef Medline

Pirri JK, McPherson AD, Donnelly JL, Francis MM Alkema MJ (2009) A tyramine-gated chloride channel coordinates distinct motor programs of a Caenorhabditis elegans escape response. Neuron 62:526-538. CrossRef Medline

Rex E, Komuniecki RW (2002) Characterization of a tyramine receptor from Caenorhabditis elegans. J Neurochem 82:1352-1359. CrossRef Medline

Ringstad N, Abe N, Horvitz HR (2009) Ligand-gated chloride channels are receptors for biogenic amines in C. elegans. Science 325:96-100. CrossRef Medline

Safratowich BD, Lor C, Bianchi L, Carvelli L (2013) Amphetamine activates an amine-gated chloride channel to generate behavioral effects in Caenorhabditis elegans. J Biol Chem 288:21630-21637. CrossRef Medline

Sanyal S, Wintle RF, Kindt KS, Nuttley WM, Arvan R, Fitzmaurice P, Bigras E, Merz DC, Hébert TE, van der Kooy D, Schafer WR, Culotti JG, Van Tol HH (2004) Dopamine modulates the plasticity of mechanosensory responses in Caenorhabditis elegans. EMBO J 23:473-482. CrossRef Medline

Sine SM, Engel AG (2006) Recent advances in Cys-loop receptor structure and function. Nature 440:448-455. CrossRef Medline

Sotnikova TD, Budygin EA, Jones SR, Dykstra LA, Caron MG, Gainetdinov RR (2004) Dopamine transporter-dependent and -independent actions of trace amine beta-phenylethylamine. J Neurochem 91:362-373. CrossRef Medline

Sotnikova TD, Beaulieu JM, Barak LS, Wetsel WC, Caron MG, Gainetdinov RR (2005) Dopamine-independent locomotor actions of amphetamines in a novel acute mouse model of Parkinson disease. PLoS Biol 3:e271. CrossRef Medline

Sugiura M, Fuke S, Suo S, Sasagawa N, Van Tol HH, Ishiura S (2005) Characterization of a novel D2-like dopamine receptor with a truncated splice variantand a D1-like dopamine receptor unique to invertebrate from Caenorhabditis elegans. J Neurochem 94:1146-1157. CrossRef Medline

Suo S, Sasagawa N, Ishiura S (2002) Identification of a dopamine receptor from Caenorhabditis elegans. Neurosci Lett 319:13-16. CrossRef Medline

Suo S, Kimura Y, Van Tol HH (2006) Starvation induces cAMP response element-binding protein-dependent gene expression through octopamine-Gq signaling in Caenorhabditis elegans. J Neurosci 26:10082-10090. CrossRef Medline

Weyler W (1992) Evidence for monoamine oxidase in Caenorhabditis elegans. Worm Breeder's Gazette 12:52.

Wragg RT, Hapiak V, Miller SB, Harris GP, Gray J, Komuniecki PR, Komuniecki RW (2007) Tyramine and octopamine independently inhibit serotoninstimulated aversive behaviors in Caenorhabditis elegans through two novel amine receptors. J Neurosci 27:13402-13412. CrossRef Medline

Yang QZ, Hatton GI (1994) Histamine mediates fast synaptic inhibition of rat supraoptic oxytocin neurons via chloride conductance activation. Neuroscience 61:955-964. CrossRef Medline 